Diskussionsbeitrag zu der Beziehung: autoradiographische Markierung/DNS-Syntheserate

\section{R. SCHRÖDER}

Max-Planck-Institut für Hirnforschung, Abteilung für Tumorforschung und experimentelle Pathologie, Köln-Lindenthal

(Z. Naturforschg. 23 b, 1123 [1968] ; eingegangen am 26. April 1968)

Quastler ${ }^{1}$ ging bei seiner Modellvorstellung über den Inkorporations-Mechanismus des Thymidins (TdR) in DNS davon aus, daß in den Zellen ein Pool von Thymidin-Triphosphat (TTP) vorliegt. Dieses Reservoir wird beeinflußt von der endogenen TdR-Produktion, durch von außen zugefügtes (z. T. markiertes) TdR, durch katabole Prozesse und durch die DNSSynthese. Dabei ist der letztgenannte Vorgang unabhängig von der Größe des TTP-Pools.

Mit autoradiographischen Methoden ist die DNSSyntheserate meßbar zugänglich in Form der mittleren Kornzahl/Kern bezogen auf bestimmte Zeiteinheiten. Ein Idealfall für die Auswertung wäre die direkte Proportionalität der so errechenbaren Anzahl inkorporierter TdR-Moleküle und der von außen angebotenen TdR-Menge. Wie Stewart und Mitarbb. ${ }^{2}$ darstellten, besteht diese Art der Abhängigkeit offenbar nur bei geringen injizierten Dosen, die allerdings höher liegen als sie bei der üblichen Technik Verwendung finden. Bei größeren Mengen kommt es zu einem „fading“, zu einer relativen Abnahme der Kornzahl. Es ist anzunehmen, daß in diesem Bereich der Pool durch die injizierte TdR-Menge so verändert wird, daß sein markierter Anteil sich einem konstanten Wert nähert, der von der spezifischen Aktivität des verwendeten ${ }^{3} \mathrm{H}$-TdR-Präparates abhängig ist.

LANG et al. ${ }^{3}$ kamen zu ähnlichen Schlußfolgerungen bei der Bestimmung des prozentualen Anteils inkorporierter markierter Vorläufer an der DNS-Synthese in Abhängigkeit von der benutzten TdR-Dosis. In ihrer Darstellung scheint jedoch die Logarithmierung der Prozentzahlen willkürlich gewählt zu sein. Würde man in diesem Koordinatensystem eine lineare Beziehung akzeptieren, so müßte die DNS ab einer bestimmten

1 H. Quastler, Effects of irradiation on synthesis and loss of DNA, in: Actions Chimiques et Biologiques des Radiations. (M. Haissinsky, ed.) Masson et Cie, Paris 1963.

2 P. A. Stewart, H. Quastler, M. R. Skougaard, D. R. Wimber, M. F. Wolfsberg, C. A. Perrotta, B. Ferbel, and M. Carlough, Radiat. Res. 24, 521 [1965].
TdR-Menge Inkorporationsraten von $>100 \%$ zeigen, was natürlich unmöglich ist. Vielmehr sollte sich auch ohne Störeffekt seitens steigender Mengen des von außen zugefügten $\mathrm{TdR}$ die Inkorporationsrate asymptotisch $100 \%$ nähern. Daher liegt es viel näher, für die Darstellung und Interpretation ein Koordinatensystem zu benutzen, wie es sich seit den grundlegenden Untersuchungen von Busss ${ }^{4}$ für Dosis-Wirkungs-Beziehungen bewährt hat. Wie die Abbildung zeigt ist die Anpassung recht gut, auch für die höheren bisher untersuchten TdR-Mengen. Die von den Autoren ${ }^{3}$ beschriebene Proportionalität bei niedrigen Dosen ist somit nur eine mehr oder weniger grobe Annäherung. Weitere Untersuchungen besonders bei noch höheren TdR-Mengen sind zur Klärung erforderlich.

Die Inkorporationsrate markierter Vorläufersubstanzen in die DNS ist nicht streng proportional der exogenen ${ }^{3} \mathrm{H}$-TdR-Menge, sondern folgt einer Verteilungsfunktion.

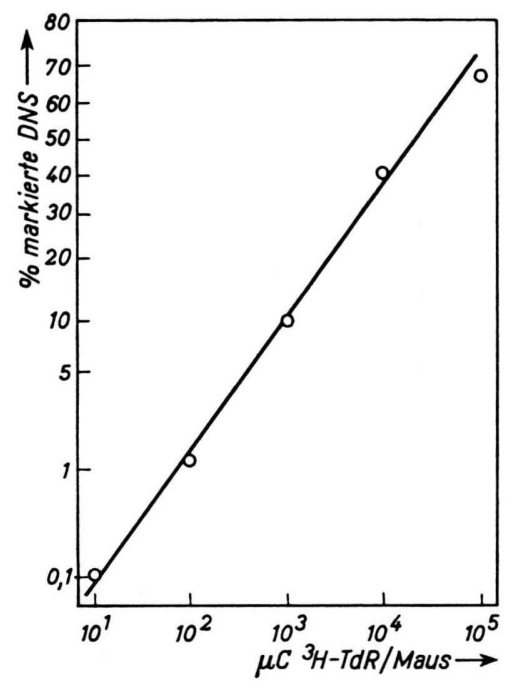

Abb. 1. Abhängigkeit der Inkorporationsrate von der ${ }^{3} \mathrm{H}$ TdR-Menge als Dosis-Wirkungsbeziehung. Nach Daten von l. c. ${ }^{3}$.

3 W. Lang, C. Pilgrim u. W. Maurer, Naturwissenschaften 53, 210 [1966].

4 C. I. BLiss, Ann. appl. Biol. 22, 134, 307 [1935]. 